\title{
Wound Healing Modulation in Glaucoma Filtration Surgery- Conventional Practices and New Perspectives: Antivascular Endothelial Growth Factor and Novel Agents (Part II)
}

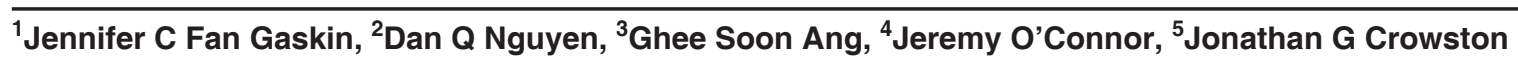

\begin{abstract}
Glaucoma filtration surgery is regularly performed for the treatment of glaucoma and trabeculectomy is often regarded as the 'gold standard' glaucoma operation. The biggest risk of failure of the operation is bleb scarring. The advent of antifibrotic agents, such as mitomycin C (MMC) and 5-fluorouracil (5FU) has vastly prolonged the longevity of the bleb, but concerns remain regarding the potential increase in postoperative complications. More selective therapeutic targets have therefore been explored. One of these is vascular endothelial growth factor (VEGF) inhibition. VEGF inhibition has a role not only in subconjunctival angiogenesis inhibition but also it has direct anti-fibrotic properties. Newer pharmacological compounds and materials have also been developed in recent years in attempt to modulate the wound healing in different ways after glaucoma surgery. These include physical barriers to scarring and vehicles for sustained release of pharmacological agents, and early promising results have been demonstrated. This two-part review will provide a discussion of the application of anti-fibrotic agents in glaucoma filtration surgery and evaluate the newer agents that have been developed.
\end{abstract}

Keywords: Glaucoma, Wound healing modulation, Filtration surgery.

How to cite this article: Fan Gaskin JC, Nguyen DQ, Ang GS, O'Connor J, Crowston JG. Wound Healing Modulation in Glaucoma Filtration Surgery-Conventional Practices and New Perspectives: Antivascular Endothelial Growth Factor and Novel Agents (Part II). J Curr Glaucoma Pract 2014;8(2):46-53.

Source of support: Nil

Conflict of interest: None

\section{INTRODUCTION}

Trabeculectomy was introduced by Cairns in 1968 and remains the most commonly performed procedure for the treatment of glaucoma. ${ }^{1,2}$ The introduction of antifibrotic

${ }^{1}$ Glaucoma Fellow, ${ }^{2-4}$ Consultant, ${ }^{5}$ Professor

1,3,5 Glaucoma Investigation and Research Unit, Centre for Eye Research, University of Melbourne, Melbourne, Australia

${ }^{2}$ Department of Ophthalmology, Mid Cheshire Hospitals, NHS Foundation Trust, Cheshire; Institute for Science and Technology in Medicine, Keele University, Keele, Staffordshire, UK

${ }^{4}$ Glaucoma Investigation and Research Unit, University Hospital Limerick, Ireland

Corresponding Author: Jennifer C Fan Gaskin, Glaucoma Fellow, Glaucoma Investigation and Research Unit, Centre for Eye Research, University of Melbourne, Melbourne, Victoria, Australia Phone: 0061406494994, e-mail: drjfan@gmail.com adjuncts, namely mitomycin $\mathrm{C}$ (MMC) and 5-fluorouracil, has significantly improved the efficacy of the traditional filtering procedure and the indications for and evidence behind the use of antimetabolites were discussed in Part I of this series. However, these substances have also been associated with the potential for increased complication rate of the filtering procedure due to their nonspecific citocidal activity, resulting in loss of the conjunctival barrier that can lead to thin-walled avascular blebs with an elevated risk of hypotony and infection. Consequently, alternative, safer forms of wound healing modulation have been sought and, in particular, agents with more specific and targeted activity. Antivascular endothelial growth factor (anti-VEGF) has been identified as a potential solution due to its more selective mode of action. Part II of this series will examine the evidence behind the use of anti-VEGF in trabeculectomy as well as discuss the newer agents/materials being developed.

\section{The Role of VEGF and Anti-VEGF in Glaucoma Filtration Surgery}

Due to the nonspecific inhibitory activity and continued risk of failure associated with antifibrotic agents, other forms of more selective wound modulation with acceptable side effects have been explored in recent years. Vascular endothelial growth factor (VEGF) plays an important role in both physiological and pathological angiogenesis throughout the body. Different VEGF isoforms may be responsible for differential roles in ocular wound healing. Van Bergen et $\mathrm{al}^{3}$ assessed the presence of VEGF in trabeculectomy blebs and reported $\operatorname{VEGF}(165)$ and $\operatorname{VEGF}(121)$ to be predominantly associated with blood vessel growth, and VEGF(189) to be involved in fibrosis. Lopilly Park et $\mathrm{al}^{4}$ analyzed the levels of VEGF in both the aqueous humor and Tenon's tissue in patients with primary open angle glaucoma (POAG) and correlated the levels with their outcome following glaucoma surgery. They identified a significant association between the VEGF level in Tenon's tissue at the time of glaucoma surgery with the 1-year intraocular pressure (IOP) and the ultimate success of the operation. Therefore by reducing angiogenesis and subsequent inflammation and collagen deposition, VEGF inhibition may have a beneficial impact on glaucoma surgical outcome. 
Bevacizumab is a recombinant humanized monoclonal immunoglobulin antibody of nonselective VEGF. In a cell culture model, bevacizumab demonstrated anti-fibrotic properties in a number of ways, including disruption of fibroblast proliferation, inhibition of collagen contractibility and induction of fibroblast cell death. ${ }^{5}$ Delayed wound healing is also a known complication of systemic bevacizumab, such as the wound dehiscence seen after colorectal surgery. ${ }^{6}$ In an early case report, Coote et $\mathrm{al}^{7}$ demonstrated significantly reduced bleb vascularity following a single subconjunctival injection of bevacizumab in an eye that had recently undergone cataract surgery 3 months post-MMC trabeculectomy.

\section{Comparison of the Efficacy of Wound Healing Modulation of Bevacizumab with Conventional Antifibrotic Agents}

Unfortunately, the number of studies comparing the efficacy of bevacizumab with conventional antifibrotic agents is small, limited in sample size and often with conflicting conclusions.

Niforushan et $\mathrm{al}^{8}$ conducted a prospective, randomized study assessing the efficacy of subconjunctival bevacizumab $(2.5 \mathrm{mg} / 0.1 \mathrm{ml} ; 18$ eyes) at the end of trabeculectomy compared with MMC-augmented trabeculectomy $(0.002 \%$ for 3 minutes; 18 eyes) and demonstrated significantly lower IOP control postoperatively in the MMC group compared to the bevacizumab group $(10 \mathrm{~mm} \mathrm{Hg}$ vs $14 \mathrm{~mm} \mathrm{Hg}$ respectively, $\mathrm{p}<0.001)$. The MMC group also had a higher cumulative probability of total success, although this was not statistically significant.

Sengupta et $\mathrm{al}^{9}$ performed a similar pilot study in patients undergoing combined phacotrabeculectomy by randomizing 38 patients into three groups: (1) conventional single-site phacotrabeculectomy with $0.3 \mathrm{mg} / \mathrm{ml}$ intraoperative MMC for 2 to 3 minutes; (2) single-site phacotrabeculectomy with three subconjunctival bevacizumab injections $(1.25 \mathrm{mg} /$ $0.05 \mathrm{ml}$ ) performed immediately prior to surgery, immediately following surgery, and on the seventh postoperative day, and (3) single-site phacotrabeculectomy with bevacizumabsoaked sponge $(1.25 \mathrm{mg} / 0.05 \mathrm{ml})$ applied intraoperatively for 3 minutes to the scleral bed. They reported subconjunctival bevacizumab to be equally effective in reducing intraocular pressure compared with MMC, only with a better safety profile. However, bevacizumab soaked in a sponge appeared to have no advantages over MMC.

When comparing bevacizumab with $5 \mathrm{FU}$, a recent study by Ozgonul et al ${ }^{10}$ analyzed the efficacy of subconjunctival 5FU compared to both subconjunctival and intravitreal bevacizumab in moderating bleb size, vascularity, and
IOP postoperatively in an animal model. They observed greater bleb length, width and height in the subconjunctival bevacizumab group compared to the other two groups. Eyes in the subconjunctival bevacizumab group also demonstrated significantly lower IOP values compared to the subconjunctival 5FU group, but not compared to the intravitreal bevacizumab group. Inflammation, neovascularization and fibrosis were correspondingly less in the subconjunctival bevacizumab group on histological analysis of the blebs.

Jurkowska-Dudzinska et $\mathrm{al}^{11}$ reported no significant differences between groups of patients who received four repeated subconjunctival bevacizumab injections $(1.25 \mathrm{mg})$ immediately before and after trabeculectomy and patients who underwent 5FU augmented trabeculectomy without postoperative bevacizumab injections. Simsek et al ${ }^{12}$ compared subconjunctival bevacizumab $(1.25 \mathrm{mg} / 0.1 \mathrm{ml})$ and $5 \mathrm{FU}(5 \mathrm{mg} / 0.2 \mathrm{ml})$ in needle revision of failed trabeculectomy blebs and reported 5FU to be more effective than bevacizumab application.

There is evidence that bevacizumab may act in synergy with 5FU. In a rabbit model of glaucoma filtration surgery, How et $\mathrm{al}^{13}$ reported that combined bevacizumab and 5FU offered superior anti-fibrotic effect over monotherapy using either agent, and at the same time prolonging bleb survival. In a randomized controlled trial, Chua et $\mathrm{al}^{14}$ observed a trend for increased central bleb avascularity after a single postoperative combined injection of bevacizumab $(1.25 \mathrm{mg} / 0.05 \mathrm{ml})$ and $5 \mathrm{FU}(7.5 \mathrm{mg} / 0.15$ $\mathrm{ml})$, compared to $5 \mathrm{FU}(7.5 \mathrm{mg} / 0.15 \mathrm{ml})$ alone. Freiberg et $\mathrm{l}^{15}$ compared postoperative subconjunctival 5FU (5 mg/ $0.5 \mathrm{ml}$ ) injections with or without one single injection of subconjunctival bevacizumab $(3.5 \mathrm{mg} / 0,14 \mathrm{ml})$ following MMC-augmented trabeculectomy in 61 patients. They demonstrated a significantly lower number of 5FU injections if bevacizumab was also administered. Whilst there was no difference in mean postoperative IOPs between the two groups, significantly fewer patients in the bevacizumab group required bleb needling in the follow-up period (mean $25 \pm$ 19 months).

There is currently no conclusive evidence as to the optimal method of delivery of anti-VEGF therapy, with the majority of published studies evaluating either subconjunctival or intravitreal injection.

\section{Novel Techniques of Modulating Postoperative Scarring in Glaucoma Filtration Surgery}

In recent years, many alternative agents and materials have been investigated for the purpose of wound modulation in glaucoma filtration surgery. In particular, research has 
focused on novel pharmacological compounds to modulate wound healing, physical barriers to limit scleral-conjunctival fibrosis, and better drug delivery of wound modulating agents. This section will provide a discussion of some of these agents. Most of these agents have only been analyzed through one or two studies and are still in the laboratory phase of development but do demonstrate some promise.

\section{Anti-Placental Growth Factor (Anti-PIGF)}

Although anti-VEGF has been demonstrated to improve surgical outcomes, the improvement is thought to occur mostly as a result of inhibition of angiogenesis rather than any significant anti-inflammatory response. ${ }^{16,17}$ Researchers have hypothesised that upregulation of placental growth factor may account for the persistent inflammatory response postfiltration surgery that cannot be inhibited by either selective or nonselective anti-VEGF. ${ }^{18-20}$ Placental growth factor (PIGF) is a VEGF-homologue that binds solely to VEGF-R1. ${ }^{21}$ It is not involved in physiological angiogenesis and acts only on pathological angiogenic and inflammatory processes. ${ }^{22,23}$ In a multifaceted study conducted by Van Bergen et $\mathrm{al},{ }^{24}$ the authors demonstrated that PIGF was upregulated by $40 \%$ in the aqueous humor of human eyes with glaucoma compared to nonglaucomatous eyes; this upregulation was locally produced as the increased PIGF was not demonstrated in the serum of the same patients. The authors also reported a further enhanced upregulation of PIGF if intravitreal bevacizumab was administered. In a mouse model of glaucoma filtration surgery, the authors reported improved surgical outcome with increasing bleb survival and bleb area following intracameral injection of anti-PIGF. This was associated with a significant reduction in cellular proliferation, inflammation and angiogenesis during the first postoperative days after surgery, and with a decrease in collagen deposition at the later stages. They hypothesized that PIGF may be a potential therapeutic target for glaucoma surgery, and proposed that a combination of optimal-dosing anti-PIGF with suboptimal-dosing antiVEGF may be more effective at reducing scar formation compared to monotherapy with either agent alone.

\section{Infliximab}

Tumor necrosis factor alpha (TNF- $\alpha$ ) has also been identified as a potential target for wound healing modulation in glaucoma filtration surgery. It is a local paracrine and autocrine regulator for low-density leukocyte and endothelial cells. It stimulates mononuclear phagocytes as well as other cell types that produce various proinflammatory cytokines and chemokines, and induces migration of polymorphic nuclear leukocytes. Infliximab is a mouse/ human chimeric monoclonal IgG1 antibody against TNF- $\alpha$. It binds to TNF- $\alpha$ and reduces both lymphocyte migration and production of proinflammatory cytokines. Its use in systemic inflammatory disorders is welldocumented, ${ }^{25}$ and it is increasingly employed to treat ocular inflammatory conditions. ${ }^{26,27}$ Turgut et al ${ }^{28}$ investigated the efficacy of post-trabeculectomy topical infliximab eye drops $(10 \mathrm{mg} / \mathrm{ml}$, four times a day for 14 days) compared with (1) intraoperative MMC $0.4 \mathrm{mg} / \mathrm{ml}$ for 3 minutes, (2) trabeculectomy with postoperative saline drops (four times a day for 14 days) (sham group), and (3) no treatment (control group) in 28 rabbits. At day 14, there were higher mean fibroblast and mononuclear cell numbers as well as higher intensities of immunofluorescent staining with transforming growth factor- $\beta$ (TGF- $\beta$ ), fibroblast growth factor- $\beta$ (FGF- $\beta$ ), and platelet-derived growth factor (PDGF) in the sham group compared to the control group. The mean inflammatory cell counts and immunostaining intensities TGF- $\beta$, FGF- $\beta$, and PDGF were lower in both the MMC group and infliximab group compared to the sham group, but there was no significant difference between the MMC group and infliximab group.

\section{Trastuzumab}

The same investigators also assessed the effects of subconjunctivally-administered trastuzumab in the rabbit model of filtration surgery. ${ }^{29}$ Trastuzumab is a humanized monoclonal antibody against the extracellular domain of the human epidermal growth factor 2 (HER2). It is most widely used in the treatment of overexpression of HER 2 in early or metastatic breast cancer, although its mechanism of action is not completely understood. ${ }^{30}$ When compared to trabeculectomy combined with intrascleral application of MMC ( $0.4 \mathrm{mg} / \mathrm{ml}$ for 3 minutes), trabeculectomy with a subconjunctival injection of trastuzumab $(1.2 \mathrm{mg} / 0.1 \mathrm{ml})$ showed comparable numbers of mononuclear cells and fibroblasts in the filtration site on histology $(p>0.05)$. Similarly, the immunostaining intensities of TGF- $\beta$, FGF- $\beta$, and PDGF were also comparable between the two groups $(p>0.05)$.

\section{Connexin43 Antisense Oligodeoxynucleotides (Cxn43 AsODN)}

Gap junctions are structures that allow direct signalling between cells. ${ }^{31}$ They play a role in inflammation, ${ }^{32}$ cell migration ${ }^{33}$ and tissue contraction. ${ }^{34}$ Gap junctions have a complex structure: Six connexin protein subunits oligomerize to form a hemichannel called a connexon; two connexons from neighboring cells dock to form a complete intercellular junction channel. Multiple intercellular channels cluster together to form gap junctions with the number of channels 
in a plaque varying considerably. ${ }^{31}$ Connexin43 (Cxn43) is one of the most ubiquitous and studied isoforms. ${ }^{35,36}$ Connexin43 antisense oligodeoxynucleotides (Cxn43 AsODN) has been demonstrated to cause a transient reduction in Cxn43 protein expression and improve cutaneous wound healing. Coutinho et $\mathrm{al}^{37}$ reported faster wound closure and smaller scar formation following partial-thickness burn wounds in mice after application of Cxn43 AsODN. Qiu et $\mathrm{al}^{38}$ also demonstrated reduced inflammation, both macroscopically and microscopically, in addition to improved wound healing following one application of Cxn43 AsODN in both incisional and excisional cutaneous wounds in rats. Deva et $\mathrm{l}^{39}$ compared the histological outcome of trabeculectomy combined with a subconjunctival injection of Cxn43 AsODN in pluronic gel with an injection balanced salt solution or pluronic gel into the formed bleb of rabbit eyes. They observed that eyes that received $\mathrm{Cxn} 43$ AsODN had reduced $\mathrm{Cx} 43$ upregulation at 8 and 24 hours post-injection, which led to less myofibroblast upregulation at days 5 and 21 and reduced scarring at day 21 compared to controls.

\section{Physical Barriers}

The concept of using amniotic membrane during glaucoma filtration surgery was first described in $1998 .{ }^{40}$ In addition to acting as a physical barrier, amniotic membrane also has additional anti-inflammatory and anti-fibrotic properties, which may further reduce the risk of scar formation. Trabeculectomy combined with amniotic membrane transplantation and MMC has shown very promising outcomes in terms of IOP control and complications for eyes with refractory glaucoma ${ }^{41,42}$ and eyes considered at high risk of surgical failure. ${ }^{43}$ However, other studies, including two randomized clinical trials, assessing primary trabeculectomy with amniotic membrane $v s$ primary trabeculectomy alone (without the use of MMC or 5FU) for POAG have demonstrated no significant benefit in IOP control at the 1 and 2-year time points. ${ }^{44-46}$ These differences in reported outcomes may partly be due to the different techniques of amniotic membrane placement as well as the use of antimetabolites. Nevertheless, the evidence base for the use of amniotic membrane in glaucoma filtration surgery currently remains inconclusive.

Expanded polytetrafluoroethylene (Gore-Tex) membrane has been assessed in glaucoma filtration surgery with some promising results. ${ }^{47-49}$ It is a nonabsorbable material that reduces tissue adhesion and fibrous capsule thickness. However, a randomized clinical trial found no significant benefit in IOP control or complication rates in primary trabeculectomy with or without expanded polytetrafluoroethylene membrane placed underneath the scleral flap. ${ }^{50}$
Various other films and materials have also been evaluated for their ability to form a physical barrier and prevent adhesions between the sclera and the conjunctiva, mostly in rabbit models. Seprafilm is a biodegradable solid film composed of hyaluronic acid and carboxymethyl cellulose. Studies of trabeculectomy have shown Seprafilm to reduce adhesions around the conjunctiva and sclera resulting in more prominent bleb formation and lower mean IOP compared to without Seprafilm. ${ }^{51,52}$ When compared to Interceed, an oxidated regenerated cellulose matrix, Seprafilm demonstrated no significant difference in IOP or bleb appearance but unfortunately, neither seemed to be able to significantly suppress the wound healing reaction following trabeculectomy. ${ }^{53}$ Correspondingly, when Interceed was evaluated in trabeculectomy alongside Surgical, another oxidated regenerated cellulose matrix, both had similar outcomes in terms of IOP, bleb appearance and lack of effect on fibroblast proliferation. ${ }^{54}$ However, a more promising option may be trabeculectomy with a honeycomb-patterned biodegradable film composed of poly(L-lactide-co- $\varepsilon$-caprolactone). This has been demonstrated to produce comparable IOP reduction and bleb survival to MMC-enhanced trabeculectomy, but without the associated complications. ${ }^{55}$

OloGen is a bioengineered, biodegradable, porous collagen-glycosaminoglycans matrix implant that is placed on top of the scleral flap and under Tenon's capsule during trabeculectomy. It was developed as a means of providing controlled resistance between the anterior chamber and the subconjunctival space in the early postoperative period. In addition, its porous structure encourages conjunctival fibroblasts and myofibroblasts to grow into the pores and secrete connective tissue in the form of a loose matrix. As a result, it reduces scar formation and wound contraction and eliminates the need for adjunctive antimetabolites. ${ }^{56,57}$ OloGen degrades naturally within 90 to 180 days of implantation.

In the rabbit model, ${ }^{56}$ significantly lower IOP was seen up to 28 days in eyes that underwent trabeculectomy with OloGen implant compared to unaugmented trabeculectomy. Histological analysis of the surgical site demonstrated loose, randomized collagen fibers in the conjunctival bleb and an unhealed scleral tunnel in the OloGen group compared to dense collagen deposition in the subconjunctival space in the control group. In a pilot study, ${ }^{58} 40$ eyes of 30 patients were randomized to either trabeculectomy with OloGen implant or unaugmented trabeculectomy alone and followed for 6 months. There was no statistically significant difference in IOP control between the two groups at 6 months: the mean IOP was comparable between the two groups (15.3 \pm 4.1 and $15.3 \pm 3.7 \mathrm{~mm} \mathrm{Hg}$, trabeculectomy with OloGen and 
unaugmented trabeculectomy respectively), and 90\% from each group achieved complete success of achieving IOP $\leq 21 \mathrm{~mm} \mathrm{Hg}$ without medication. Although not statistically significant, one eye from the OloGen group developed endophthalmitis 10 days after initial surgery and required vitreoretinal intervention. Five eyes from the control group and two eyes from the OloGen group developed bleb encystment at 1 month post-trabeculectomy and all patients required treatment with subconjunctival 5FU injections postoperatively (number of injections ranged 2-7).

Subsequently, several randomized controlled trials have compared MMC-augmented trabeculectomy with OloGen-implanted trabeculectomy with varying results. In the largest RCT evaluating 40 eyes of 40 patients, Cillion et al found no significant difference in terms of IOP control and complications between the two groups at up to 24 months' follow-up. ${ }^{57}$ In 39 eyes of 33 subjects, Senthill et $\mathrm{al}^{59}$ observed lower IOP in the MMC group at 6 months compared to the OloGen group, but no significant difference at 12 or 24 months. On the contrary, Rosentreter et $\mathrm{al}^{60}$ demonstrated significantly lower IOP in MMCaugmented trabeculectomy compared to OloGen-augmented trabeculectomy in 20 eyes of 20 patients at 1 year; $100 \%$ of eyes in the MMC group achieved complete success of IOP $\leq 18 \mathrm{~mm} \mathrm{Hg}$ and only $50 \%$ of eyes in OloGen groups achieved complete success at 1 year. However, they also reported more avascularity in the MMC-augmented blebs than the OloGen-treated blebs in this study. ${ }^{60}$

The use of OloGen implantation has also extended to phacotrabeculectomies and Ex-Press shunts, again with varying reported results when compared to MMC. ${ }^{61,62}$

Another biodegradable implant composed of collagen glycosaminoglycan matrices (CGM) has been introduced for the treatment of post-trabeculectomy hypotony. The implant is inserted subconjunctivally through an incision adjacent to the bleb and placed over the scleral flap. In a pilot study of 12 eyes, IOP increased from a mean of 4 to $10 \mathrm{~mm} \mathrm{Hg}$ after an average follow-up of 6 months. ${ }^{63}$ In this study, one patient developed implant exposure, one developed a corneal dellen adjacent to the implant, and two patients required topical hypotensive medication at the end of the follow-up period. ${ }^{63}$

\section{Drug Delivery of Current Pharmacological Agents}

Alternative methods of delivering antimetabolites in a sustained yet safe manner was discussed in Part I of this review. In this section, the focus will be on novel forms of drug delivery of other pharmacological agents.

As previously discussed in Part I, various hydrogels have been evaluated in animal models for their ability to provide slow, sustained release of incorporated wound healing modulators. In addition to anti-fibrotic agents, hydrogels have also been developed to incorporate other pharmacological agents for use in animal trabeculectomy models. Carbopol 980 hydrogel loaded with paclitaxel demonstrated anti-fibrotic effects on rabbit conjunctival wound healing that was similar to that of MMC alone. ${ }^{64}$ In canine trabeculectomy, implantation of a gelatin hydrogel chymase inhibitor combination reduced cell proliferation and better maintained IOP at 12 weeks compared to controls. ${ }^{65}$ Other novel hydrogels include a bioactive self-assembled peptide that can be used either alone or loaded with 5FU in glaucoma filtration surgery. ${ }^{66,67}$ These hydrogel-compounds are still in the experimental phase.

A new bevacizumab-loaded polyurethane subconjunctival implant has been developed in a rabbit model designed to be inserted adjacent to the filtration site on the episclera. ${ }^{68}$ Compared to the rabbit eyes with non-bevacizumab-loaded polyurethane implants, the eyes with bevacizumab-loaded implants did not demonstrate significant differences in bleb area in vivo or collagen density ex vivo. However, there was a significantly lower number of VEGF-expressing fibroblasts in the bevacizumab group.

The interest in sodium hyaluronate stems from its utility in sustained drug delivery as well as its inherent antifibrotic properties and ability to act as a physical spacer. When loaded with dexamethasone, it allowed extended release of the steroid at concentrations sufficient for antiproliferative activity over a period of nearly 2 days. ${ }^{69}$ Two randomized clinical trials evaluated the benefit of subconjunctival hyaluronate in glaucoma surgery: the first at the conclusion of trabeculectomy, ${ }^{70}$ and the second when performed in conjunction with bleb needling for failing trabeculectomy blebs. ${ }^{71}$ Lopes et al reported no significant difference in success rates when comparing subconjunctival sodium hyaluronate $2.3 \%$ against balanced salt solution at the conclusion of trabeculectomy after a mean follow-up of 12 months. ${ }^{70}$ Naravanaswamy et al compared a 5FU and hyaluronate $2.3 \%$ mixture $v s 5 \mathrm{FU}$ alone in bleb needling of failing blebs and found no significant differences in outcomes at 3 months although the 5FU alone group required repeat needling more frequently. ${ }^{71}$ A retrospective case series with longer follow-up of 12 months found of bleb needling with subconjunctival sodium hyaluronate $1.4 \%$ and $5 \mathrm{FU}$ to be effective for reducing intraocular pressure in the medium term with few serious complications. ${ }^{72}$

Another approach that has received keen research interest is microfilms loaded with pharmacological agents. Microfilms composed of poly (D-, L-lactide-co-caprolactone) and loaded with prednisolone acetate provided steady, sustained release of prednisolone in vitro; subconjunctival implantation reduced postoperative inflammation and prolonged bleb survival in rabbit trabeculectomy. ${ }^{73}$ A sirolimus sustained- 
delivery film composed of polyactioglyconic acid polymer also showed similar anti-inflammatory effects after filtration surgery in a rabbit model. ${ }^{74}$

\section{CONCLUSION}

Glaucoma filtration surgery has an indisputable place in the management of glaucoma but efforts to minimize complications associated with antifibrotic use remain ongoing. Significant research is being conducted on newer, alternative forms of trabeculectomy wound modulation. Agents such as anti-VEGF and other novel pharmacological compounds have shown promise, but require confirmation and refinement in application through larger, prospective clinical trials. It is an exciting evolving era for glaucoma wound modulation, and undoubtedly the humble trabeculectomy will be undergoing a facelift in the near future.

\section{REFERENCES}

1. Cairns JE. Trabeculectomy. Preliminary report of a new method. Am J Ophthalmol 1968 Oct;66(4):673-679.

2. Spaeth GL. A prospective, controlled study to compare the Scheie procedure with Watson's trabeculectomy. Ophthalmic Surg 1980 Oct;11(10):688-694.

3. Van Bergen T, Vandewalle E, Van de Veire S, Dewerchin M, Stassen JM, Moons L, Stalmans I. The role of different VEGF isoforms in scar formation after glaucoma filtration surgery. Exp Eye Res 2011 Nov;93(5): 689-699.

4. Lopilly Park HY, Kim JH, Ahn MD, Park CK. Level of vascular endothelial growth factor in tenon tissue and results of glaucoma surgery. Arch Ophthalmol 2012 Jun;130(6):685-689.

5. O'Neill EC, Qin Q, Van Bergen NJ, Connell PP, Vasudevan S, Coote MA, Trounce IA, Wong TT, Crowston JG. Antifibrotic activity of bevacizumab on human Tenon's fibroblasts in vitro. Invest Ophthalmol Vis Sci 2010 Dec;51(12):6524-6532.

6. August DA, Serrano D, Poplin E.” Spontaneous,“delayed colon and rectal anastomotic complications associated with bevacizumab therapy. J Surg Oncol 2008 Feb 1;97(2):180-185.

7. Coote MA, Ruddle JB, Qin Q, Crowston JG. Vascular changes after intra-bleb injection of bevacizumab. J Glaucoma 2008 Oct-Nov;17(7):517-518.

8. Nilforushan N, Yadgari M, Kish SK, Nassiri N. Subconjunctival bevacizumab versus mitomycin $\mathrm{C}$ adjunctive to trabeculectomy. Am J Ophthalmol 2012 Feb;153(2):352-357.e351.

9. Sengupta S, Venkatesh R, Ravindran RD. Safety and efficacy of using off-label bevacizumab versus mitomycin $C$ to prevent bleb failure in a single-site phacotrabeculectomy by a randomized controlled clinical trial. J Glaucoma 2012 Sep;21(7):450-459.

10. Ozgonul C, Mumcuoglu T, Gunal A. The effect of bevacizumab on wound healing modulation in an experimental trabeculectomy model. Curr Eye Res 2014 May;39(5):451-459.

11. Jurkowska-Dudzinska J, Kosior-Jarecka E, Zarnowski T. Comparison of the use of 5-fluorouracil and bevacizumab in primary trabeculectomy: results at 1 year. Clin Experiment Ophthalmol 2012 May-Jun;40(4):e135-e142.

12. Simsek T, Cankaya AB, Elgin U. Comparison of needle revision with subconjunctival bevacizumab and 5-fluorouracil injection of failed trabeculectomy blebs. J Ocul Pharmacol Ther 2012 Oct;28(5):542-546.
13. How A, Chua JL, Charlton A, Su R, Lim M, Kumar RS, Crowston JG, Wong TT. Combined treatment with bevacizumab and 5-fluorouracil attenuates the postoperative scarring response after experimental glaucoma filtration surgery. Invest Ophthalmol Vis Sci 2010 Feb;51(2):928-932.

14. Chua BE, Nguyen DQ, Qin Q, Ruddle JB, Wells AP, Niyadurupola N, Gupta V, Wong TT, Coote MA, Crowston JG. Bleb vascularity following post-trabeculectomy subconjunctival bevacizumab: a pilot study. Clin Experiment Ophthalmol 2012 Nov;40(8): 773-779.

15. Freiberg FJ, Matlach J, Grehn F, Karl S, Klink T. Postoperative subconjunctival bevacizumab injection as an adjunct to 5 -fluorouracil in the management of scarring after trabeculectomy. Clin Ophthalmol 2013;7:1211-1217.

16. Wilgus TA, Ferreira AM, Oberyszyn TM, Bergdall VK, Dipietro LA. Regulation of scar formation by vascular endothelial growth factor. Lab Invest 2008 Jun;88(6):579-590.

17. Mello GR, Pizzolatti ML, Wasilewski D, Santhiago MR, Budel $\mathrm{V}$, Moreira $\mathrm{H}$. The effect of subconjunctival bevacizumab on corneal neovascularization, inflammation and re-epithelization in a rabbit model. Clinics (Sau Paulo) 2011;66(8):1443-1450.

18. Batchelor TT, Sorensen AG, di Tomaso E, Zhang WT, Duda DG, Cohen KS, Kozak KR, Cahill DP, Chen PJ, Zhu M, et al. AZD2171, a pan-VEGF receptor tyrosine kinase inhibitor, normalizes tumor vasculature and alleviates edema in glioblastoma patients. Cancer Cell 2007 Jan;11(1):83-95.

19. Motzer RJ, Michaelson MD, Redman BG, Hudes GR, Wilding G, Figlin RA, Ginsberg MS, Kim ST, Baum CM, DePrimo SE, et al. Activity of SU11248, a multitargeted inhibitor of vascular endothelial growth factor receptor and platelet-derived growth factor receptor, in patients with metastatic renal cell carcinoma. J Oncol 2006 Jan 1;24(1):16-24.

20. Willett CG, Boucher Y, Duda DG, di Tomaso E, Munn LL, Tong RT, Kozin SV, Petit L, Jain RK, Chung DC, et al. Surrogate markers for antiangiogenic therapy and dose-limiting toxicities for bevacizumab with radiation and chemotherapy: continued experience of a phase I trial in rectal cancer patients. J Clin Oncol 2005 Nov 1;23(31):8136-8139.

21. Ribatti D. The discovery of the placental growth factor and its role in angiogenesis: a historical review. Angiogenesis 2008; 11(3):215-221.

22. Carmeliet P, Moons L, Luttun A, Vincenti V, Compernolle V, De Mol M, Wu Y, Bono F, Devy L, Beck H, et al. Synergism between vascular endothelial growth factor and placental growth factor contributes to angiogenesis and plasma extravasation in pathological conditions. Nat Med 2001 May;7(5):575-583.

23. Luttun A, Tjwa M, Moons L, Wu Y, Angelillo-Scherrer A, Liao F, Nagy JA, Hooper A, Priller J, De Klerck B, et al. Revascularization of ischemic tissues by PlGF treatment and inhibition of tumor angiogenesis, arthritis and atherosclerosis by anti-Flt1. Nat Med 2002 Aug;8(8):831-840.

24. Van Bergen T, Jonckx B, Hollanders K, Sijnave D, Van de Velde S, Vandewalle E, Moons L, Stassen JM, Stalmans I. Inhibition of placental growth factor improves surgical outcome of glaucoma surgery. J Cell Mol Med 2013 Dec;17(12):1632-1643.

25. Ebert EC. Infliximab and the TNF-alpha system. Am J Physiol Gastrointest Liver Physiol 2009 Mar;296(3):612G-620G.

26. Hosseini H, Safaei A, Khalili MR, Nowroozizadeh B, Eghtedari M, Farvardin M, Nowroozizadeh S, Tolide-Ie HR. Intravitreal infliximab in experimental endotoxin-induced uveitis. Eur J Ophthalmol 2009 Sep-Oct;19(5):818-823. 
27. Demir T, Gödekmerdan A, Balbaba M, Türkçüoglu P, Ilhan F, Demir N. The effect of infliximab, cyclosporine A and recombinant IL-10 on vitreous cytokine levels in experimental autoimmune uveitis. Indian J Ophthalmol 2006 Dec;54(4):241-245.

28. Turgut B, Eren K, Akin MM, Demir T, Kobat S. Topical infliximab for the suppression of wound healing following experimental glaucoma filtration surgery. Drug Des Devel Ther 2014 May 2;8:421-429.

29. Turgut B, Eren K, Akin MM, Bilir Can N, Demir T. Impact of trastuzumab on wound healing in experimental glaucoma surgery. Clin Experiment Ophthalmol 2014 May 7.

30. Valabrega G, Montemurro F, Aglietta M. Trastuzumab: mechanism of action, resistance and future perspectives in HER2-overexpressing breast cancer. Ann Oncol 2007 Jun;18(6):977-984.

31. Evans WH, De Vuyst E, Leybaert L. The gap junction cellular internet: connexin hemichannels enter the signalling limelight. Biochem J 2006 Jul 1;397(1):1-14.

32. Beyer EC, Steinberg TH. Evidence that the gap junction protein connexin-43 is the ATP-induced pore of mouse macrophages. J Biol Chem 1991 May 5;266(13):7971-7974.

33. Oviedo-Orta E, Errington RJ, Evans WH. Gap junction intercellular communication during lymphocyte transendothelial migration. Cell Biol Int 2002;26(3):253-263.

34. Ehrlich HP, Gabbiani G, Meda P. Cell coupling modulates the contraction of fibroblast-populated collagen lattices. J Cell Physiol 2000 Jul;184(1):86-92.

35. Goodenough DA, Goliger JA, Paul DL. Connexins, connexons and intercellular communication. Annu Rev Biochem 1996;65:475-502.

36. Kumar NM, Gilula NB. The gap junction communication channel. Cell 1996 Feb 9;84(3):381-388.

37. Coutinho P, Qiu C, Frank S, Wang CM, Brown T, Green CR, Becker DL. Limiting burn extension by transient inhibition of Connexin 43 expression at the site of injury. Br J Plast Surg 2005 Jul;58(5):658-667.

38. Qiu C, Coutinho P, Frank S, Franke S, Law LY, Martin P, Green CR, Becker DL. Targeting connexin43 expression accelerates the rate of wound repair. Curr Biol 2003 Sep 30;13(19):1697-1703.

39. Deva NC, Zhang J, Green CR, Danesh-Meyer HV. Connexin43 modulation inhibits scarring in a rabbit eye glaucoma trabe culectomy model. Inflammation 2012 Aug;35(4):1276-1286.

40. Fujishima H, Shimazaki J, Shinozaki N, Tsubota K. Trabeculectomy with the use of amniotic membrane for uncontrollable glaucoma. Ophthalmic Surg Lasers 1998 May;29(5):428-431.

41. Drolsum L, Willoch C, Nicolaissen B. Use of amniotic membrane as an adjuvant in refractory glaucoma. Acta Ophthalmol Scand 2006 Dec;84(6):786-789.

42. Sheha H, Kheirkhah A, Taha H. Amniotic membrane trans plantation in trabeculectomy with mitomycin $\mathrm{C}$ for refractory glaucoma. J Glaucoma 2008 Jun-Jul;17(4):303-307.

43. Bruno CA, Eisengart JA, Radenbaugh PA, Moroi SE. Subconjunctival placement of human amniotic membrane during high risk glaucoma filtration surgery. Ophthalmic Surg Lasers Imaging 2006 May-Jun;37(3):190-197.

44. Eliezer RN, Kasahara N, Caixeta-Umbelino C, Pinheiro RK, Mandia C Jr, Malta RF. Use of amniotic membrane in trabeculectomy for the treatment of glaucoma: a pilot study. Arq Bras Oftalmol 2006 May-Jun;69(3):309-312.
45. Stavrakas P, Georgopoulos G, Milia M, Papaconstantinou D, Bafa M, Stavrakas E, Moschos M. The use of amniotic membrane in trabeculectomy for the treatment of primary open-angle glaucoma: a prospective study. Clin Ophthalmol 2012;6:205-212.

46. Nakamura M, Naka M, Tatsumi Y, Nagai-Kusuhara A, Kanamori A, Yamada Y, Negi A. Filtering bleb structure associated with long-term intraocular pressure control after amniotic membrane-assisted trabeculectomy. Curr Eye Res 2012 Mar;37(3):239-250.

47. Kim C, Kim Y, Choi S, Lee S, Ahn B. Clinical experience of e-PTFE membrane implant surgery for refractory glaucoma. Br J Ophthalmol 2003 Jan;87(1):63-70.

48. Choi YJ, Kim CS, Ahn BH. A comparison of the clinical effect between e-PTFE membrane-tube implant and Ahmed glaucoma valve implant for the treatment of refractory glaucoma. Korean J Ophthalmol 2003 Dec;17(2):106-113.

49. DeCroos FC, Ahmad S, Kondo Y, Chow J, Mordes D, Lee MR, Asrani S, Allingham RR, Olbrich KC, Klitzman B. Expanded polytetrafluoroethylene membrane alters tissue response to implanted Ahmed glaucoma valve. Curr Eye Res 2009 Jul;34(7): 562-567.

50. Cillino S, Zeppa L, Di Pace F, Casuccio A, Morreale D, Bocchetta F, Lodato G. E-PTFE (Gore-Tex) implant with or without low-dosage mitomycin-C as an adjuvant in penetrating glaucoma surgery: 2 year randomized clinical trials. Acta Ophthalmol 2008 May;86(3):314-321.

51. Takeuchi K, Nakazawa M, Yamazaki H, Miyagawa Y, Ito T, Ishikawa F, Metoki T. Solid hyaluronic acid film and the prevention of postoperative fibrous scar formation in experimental animal eyes. Arch Ophthalmol 2009 Apr;127(4):460-464.

52. Tsurumaru N, Arai M, Teruya K, Sueda J, Yamakawa R. Seprafilm as a new antifibrotic agent following trabeculectomy in rabbit eyes. Jpn J Ophthalmol 2009 Mar;53(2):164-170.

53. Akyol N, Aydogan S, Akpolat N. Effects of membrane adhesion barriers on wound healing reaction after glaucoma filtration surgery: a comparative study with Interceed and Seprafilm. Eur J Ophthalmol 2005 Sep-Oct;15(5):591-597.

54. Akyol N, Akpolat N. Effects of intraoperative oxidated regenerated cellulose on wound healing reaction after glaucoma filtration surgery: a comparative study with Interceed and Surgicel. Indian J Ophthalmol 2008 Mar-Apr;56(2):109-114.

55. Okuda T, Higashide T, Fukuhira Y, Sumi Y, Shimomura M, Sugiyama K. A thin honeycomb-patterned film as an adhesion barrier in an animal model of glaucoma filtration surgery. $\mathrm{J}$ Glaucoma 2009 Mar;18(3):220-226.

56. Hsu WC, Ritch R, Krupin T, Chen HS. Tissue bioengineering for surgical bleb defects: an animal study. Graefes Arch Clin Exp Ophthalmol 2008 May;246(5):709-717.

57. Cillino S, Di Pace F, Cillino G, Casuccio A. Biodegradable collagen matrix implant vs mitomycin-C as an adjuvant in trabeculectomy: a 24-month, randomized clinical trial. Eye (Lond) 2011 Dec;25(12):1598-1606.

58. Papaconstantinou D, Georgalas I, Karmiris E, Diagourtas A, Koutsandrea C, Ladas I, Apostolopoulos M, Georgopoulos G. Trabeculectomy with OloGen versus trabeculectomy for the treatment of glaucoma: a pilot study. Acta Ophthalmol 2010 Feb; 88(1):80-85. 
59. Senthil S, Rao HL, Babu JG, Mandal AK, Garudadri CS. Comparison of outcomes of trabeculectomy with mitomycin C vs. ologen implant in primary glaucoma. Indian J Ophthalmol 2013 Jul;61(7):338-342.

60. Rosentreter A, Schild AM, Jordan JF, Krieglstein GK, Dietlein TS. A prospective randomised trial of trabeculectomy using mitomycin $\mathrm{C}$ vs an ologen implant in open angle glaucoma. Eye (Lond) 2010 Sep;24(9):1449-1457.

61. Narayanaswamy A, Perera SA, Htoon HM, Hoh ST, Seah SK, Wong TT, Aung T. Efficacy and safety of collagen matrix implants in phacotrabeculectomy and comparison with mitomycin $\mathrm{C}$ augmented phacotrabeculectomy at 1 year. Clin Experiment Ophthalmol 2013 Aug;41(6):552-560.

62. Johnson MS, Sarkisian SR Jr. Using a collagen matrix implant (Ologen) versus mitomycin-C as a wound healing modulator in trabeculectomy with the Ex-PRESS mini glaucoma device: a 12-month retrospective review. J Glaucoma 2014 Dec;23(9):649-652.

63. Dietlein TS, Lappas A, Rosentreter A. Secondary subconjunctival implantation of a biodegradable collagen-glycosaminoglycan matrix to treat ocular hypotony following trabeculectomy with mitomycin C. Br J Ophthalmol 2013 Aug;97(8):985-988.

64. Koz OG, Ozhuy S, Tezel GG, Karaman N, Unlu N, Yarangumeli A, Kural G. The effect of paclitaxel on conjunctival wound healing: a pilot study. J Glaucoma 2007 Oct-Nov;16(7):610-615.

65. Kojima S, Sugiyama T, Takai S, Jin D, Shibata M, Oku H, Tabata Y, Ikeda T. Effects of gelatin hydrogel containing chymase inhibitor on scarring in a canine filtration surgery model. Invest Ophthalmol Vis Sci 2011 Sep 29;52(10):7672-7680.

66. Liang L, Xu XD, Zhang XZ, Feng M, Peng C, Jiang FG. Prevention of filtering surgery failure by subconjunctival injection of a novel peptide hydrogel into rabbit eyes. Biomed Mater 2010 Aug;5(4):045008.
67. Xu XD, Liang L, Chen CS, Lu B, Wang NL, Jiang FG, Zhang $\mathrm{XZ}$, Zhuo RX. Peptide hydrogel as an intraocular drug delivery system for inhibition of postoperative scarring formation. ACS Appl Mater Interfaces 2010 Sep;2(9):2663-2671.

68. Paula JS, Ribeiro VR, Chahud F, Cannellini R, Monteiro TC, Gomes EC, Reinach PS, Rodrigues Mde L, Silva-Cunha A. Bevacizumab-loaded polyurethane subconjunctival implants: effects on experimental glaucoma filtration surgery. J Ocul Pharmacol Ther 2013 Jul-Aug;29(6):566-573.

69. Spitzer MS, Yoeruek E, Kaczmarek RT, Sierra A, Aisenbrey S, Grisanti S, Bartz-Schmidt KU, Szurman P. Sodium hyaluro nate gels as a drug-release system for corticosteroids: release kinetics and antiproliferative potential for glaucoma surgery. Acta Ophthalmol 2008 Dec;86(8):842-848.

70. Lopes JF, Moster MR, Wilson RP, Altangerel U, Alvim HS, Tong MG, Fontanarosa J, Steinmann WC. Subconjunctival sodium hyaluronate $2.3 \%$ in trabeculectomy: a prospective randomized clinical trial. Ophthalmology 2006 May;113(5):756-760.

71. Narayanaswamy AK, Lee K, Zhen M, Chua J, Chai SM, Boey PY, Zheng C, Aung T, Venkatraman S, Wong TT. Randomized, controlled trial of a sustained delivery formulation of 5-fluo rouracil for the treatment of failing blebs. Ophthalmology 2012 Feb;119(2):314-320.

72. Shafi F, Agrawal P, Holder R, Sung V. Bleb needling with subconjunctival injection of sodium hyaluronate 1.4\%: 1-year outcomes. Can J Ophthalmol 2011 Dec;46(6):537-542.

73. Ang M, Yan P, Zhen M, Foo S, Venkatraman SS, Wong TT. Eva luation of sustained release of PLC-loaded prednisolone acetate microfilm on postoperative inflammation in an experimental model of glaucoma filtration surgery. Curr Eye Res 2011 Dec;36(12):1123-1128.

74. Yan ZC, Bai YJ, Tian Z, Hu HY, You XH, Lin JX, Liu SR, Zhuo YH, Luo RJ. Anti-proliferation effects of Sirolimus sustained delivery film in rabbit glaucoma filtration surgery. Mol Vis 2011;17:2495-2506. 